\title{
Toward a Formal Approach to Process Bundling in Public Administrations
}

\author{
Marlen Jurisch, Petra Wolf, and Helmut Krcmar \\ Technische Universität München, Chair for Information Systems I17, Boltzmannstr. 3, \\ 85748 Garching bei München \\ \{marlen.jurisch, petra.wolf, krcmar\}@in.tum.de
}

\begin{abstract}
Excessive information and data exchanges between companies and public administrations create a need for the bundling of processes. Process bundles are created whenever cross-organizational processes are combined or interlinked. While a considerable amount of literature addressing the process of reorganizing, optimizing, or reengineering processes exists, much less is known about concrete approaches which facilitate the identification of suitable process bundles. This paper presents a review of identification criteria relevant for process bundling. Our literature review is deliberately broad, encompassing work in the fields of process management, reengineering, and E-Government. The analysis discloses that the plain focus on secondary process identification criteria (e.g., inefficiencies and redundancies) neglects to assess if the processes actually fit together. Premised on these results, we synthesize the insights from the cited literature into a methodological intermediary step to support the purposeful elicitation of bundling candidates.
\end{abstract}

Keywords: process bundling, business-to-government, process identification.

\section{Introduction and Context}

Municipalities are confronted with constant cost and performance pressures. More so, citizens and businesses demand increased customer orientation and an integration of their needs. This entails a change in how public administrations deliver their services and processes, e.g.: availability of services (e-services), quality of services, timeliness of service delivery, etc [1]. Nowadays, process changes triggered by cost and performance pressures are often driven by technology. Nonetheless, quality and service goals will not be achieved by the mere introduction of technology [2]. The uninterrupted execution of public services coupled with the simultaneous increase in customer orientation, requires an automation of the underpinning public service processes. The optimization of public service processes demands an identification of suitable bundling candidates. For the bundling of processes the identification and selection of appropriate processes is particularly crucial. Yet, this identification of suitable process bundling candidates has proved to be rather complex in practice [3]. Even though most of the existing literature addresses the reorganization, optimization or the reengineering of business processes, very little work has been dedicated to the 
actual identification of suitable process bundles. This state of affairs led us to the following research question: What are the criteria for the identification of suitable process bundling candidates?

The question of "how" to model processes and technical procedures for implementing business process improvements in organizations has been addressed in the literature [4] [5]. Further, several methods, techniques, and tools have been developed and implemented to support process oriented reorganizations within companies [1] [6]. In recent years, process improvement efforts were also undertaken in the area of public administration. Within the context of public institutions, the discussion of public process improvement is often limited to the provision of online services and public administrations' internet portals [7]. In the business domain, an abundance of different business process improvement methodologies exist but only a selected few of these focus specifically on process optimization in public institutions [1] [6]. The theoretical and practical knowledge acquired within the private sector on process improvement has been insufficiently translated and applied into the public sector. Further, the urgent practical challenges faced in the public sector with regards to process improvement have, so far, not been adequately addressed by the relevant academic disciplines. In order to identify a holistic set of criteria for the identification of public service process bundles it is necessary to review common business process improvement methodologies.

We begin this paper by delineating the term process bundling and the undergirding reasons for bundling processes in public administrations. This is followed by a presentation of the method we used for reviewing the relevant literature. We then analyze this literature and synthesize the results into a methodological intermediary step. Finally, we discuss our findings, outline avenues for future research, and suggest implications for practice.

\section{Process Bundles in Public Administrations}

\subsection{What Is Process Bundling?}

Bureaucracies are characterized by intense flows of information. Over $90 \%$ of all administrative processes are information-processing in nature [8]. Due to their large and often redundant number of functions and functional departments, public institutions are likely to be affected by excessive information and data exchanges across functional departments and with companies. This situation is caused by the fundamental principles of traditional public administrations: bureaucracy, hierarchical organization, bureaucratic delivery, politics/administration dichotomy, etc. [9]. Common business concepts such as value creation, competitive edge, or profit maximization [10] are typically not the foci of public administrations. Rather, public administrations are concerned with the process and delivery of public services to citizens, businesses, and to other governmental institutions. As a result, processes in public institutions need to be understood as reporting duties on the basis of legal requirements [3]. Thus, public service processes are concerned with monitoring compliance to legal regulations and the execution of public services. Public service 
processes involve a large number of recurrent activities [1] [11], extensive integration of customers, and numerous points of interaction [5]. The excessive information and data exchanges in the public sphere create a fertile ground for the bundling of processes.

From a customer perspective, process bundles are created whenever crossorganizational processes are combined or interlinked either organizationally or technically with the objective to create a coherent data base. Hence, a process bundle, within the remit of public administrations, constitutes the purposeful alignment of separate activities, and accordingly processes, along a well-defined value chain [12]. Let us take the example of a real-estate loan award. Throughout this award process the bank needs to maintain contacts with numerous public institutions which do not necessarily have a technically supported infrastructure and are often dependent on manual labor (i.e., fiscal authorities, notary, land registry, bankruptcy court, etc.) [13] [14]. The bundling of these activities through technical interlinking would result in the uninterrupted and efficient execution of the loan award process. According to this understanding, process bundling is concerned with changing or redirecting the flow of information between activities without changing the actual content of the information.

\subsection{Reasons for Bundling}

The concept of bundling processes or services is neither new nor revolutionary. Particularly in the service domain, bundling has been on the research agenda for over a decade. Streamlining public service processes also implies streamlining their output, which are in fact, the delivered services. To support our arguments presented in this paper, we would like to draw on some of the knowledge of the service domain on bundling.

Our review of the literature on the service domain disclosed that the rationale behind bundling varies in complexity. Nevertheless, two reasons prevail - increasing profits and saving costs. Due to their nature and tasks, municipalities are non- profit oriented. Hence, increasing profits does not provide an adequate reason to support process bundling in public administrations. Saving costs, on the other hand, is a persistent issue and fundamental aspect of the operation of public institutions. The omnipresent financial restrictions forces municipalities to operate cost-efficiently and customer-oriented. The German government, for instance, anticipates cutting the costs of bureaucracy by over $15 \%$ through the implementation of process bundling [15] and the streamlining of processes is expected to result in faster through-put times of administrative procedures. It has been proposed that cost savings can occur through a joined transaction of the bundle components and their joined distribution [16].

Another reason for process bundling is to ease the interaction of public authorities with businesses through the synchronization and integration of processes and ITapplications. To accomplish this, legal regulations and public service processes need to be revised critically and, if necessary, adjusted [15]. If employed successfully, process bundling yields the electronic and uninterrupted processing of public service processes. Therefore, existing bureaucratic structures need to be reassessed with the aim of creating more effective and flexible organizations via process bundling. 


\section{Methodology Used for the Literature Review}

The literature review comprised two phases: identification and analysis. In the identification phase we identified and selected research studies which discussed process identification criteria. We assembled a comprehensive collection of publications representing the main body of knowledge in this area. The analysis entailed a careful scrutiny of publications to unveil patterns of commonly addressed research themes.

\subsection{Identification of Relevant Literature}

Most process reorganization or optimization approaches include a phase for tackling the identification of processes [1] [17-21]. The identification of the right bundling candidates is crucial to the success of process-optimizations and reorganizations [17] [18]. The bundling of inadequate processes could have extensive implications on the organization's operating capabilities. Frequently, process reorganization or optimization projects are burdened by a plethora of information which makes it difficult to identify suitable process bundling candidates. The potential measures are not only numerous (see table 1), but some of them are difficult to operationalize in public administrations. Consequently, purposeful bundling requires a set of welldefined identification criteria.

The identification phase commenced with an initial search for publications relevant to process identification and several sources were consulted for this search. The most important sources were academic books, journals and conference proceedings. The search mechanism included identification of keywords such as process identification, integration, selection, and modeling. As a result, we identified an initial set of 36 relevant publications. We then screened this initial set of publications to select the most significant ones. The screening was conducted on the basis of the quality of the research studies, their relevance to process identification, and their citation frequency. The screening cycle yielded a final set of 15 key research studies which represent the basis of the literature review.

\subsection{Structuring the Review}

Criteria for the identification of process integration candidates are both abundant and diverse (see table 1). As suggested in the literature [19], we implemented a conceptcentric literature review. Based on this review, we conceptualize that the majority of relevant process identification criteria can be categorized according to the following three identification principles: (1) performance, (2) process integration, and (3) complexity (see table 1 ). These three categories are not mutually exclusive.

\section{Analysis - Identification of Process Bundling Candidates}

A plethora of diverse approaches for improving processes exists in various disciplines. Information systems, industrial engineering, operations research, and management accounting are among the disciplines represented [17]. In the following, we present the results of the literature analysis structured according to these three categories. 
Table 1. Principles of process identification

\begin{tabular}{lll}
\hline Principle & Criteria & Source \\
\hline \multirow{3}{*}{ Performance } & $\begin{array}{l}\text { Through-put time, costs (of bureaucracy), [1] [5] [11] [18] } \\
\text { quality, customer satisfaction, value } \\
\text { proposition }\end{array}$ & {$[20][21][22][23]$} \\
& $\begin{array}{l}\text { Information flow, degree of information } \\
\text { integration, timeliness, access, granularity, [5] [24] [25] [26] }\end{array}$ \\
$\begin{array}{l}\text { Process } \\
\text { integration }\end{array}$ & $\begin{array}{l}\text { Number of cases, exceptions, special cases } \\
\text { classification of actors }\end{array}$ & [20] [21] [27] [29] \\
\hline Complexity &
\end{tabular}

\subsection{Performance Indicators}

Parameters assessing the process' performance and efficiency were among the most frequently listed. Nearly all process reorganization and optimization approaches depict criteria influencing the performance of a process. Gaitanides [21] asserts that optimization potentials can be identified through the analysis of simple data parameters such as through-put time, costs, and quality. Through-put time analyzes the processing time, the transfer time, and the holding time of a process. The primary goal is, of course, the frictionless organization of processes. Therefore, holding times need to be reduced, and unproductive times need to be detected and eliminated. The identification of cost intensive and "non-value" adding processes is the key objective of the cost assessment [21]. Higher costs are often caused by redundancies and inefficient workflow between activities. However, obtaining accurate data on costs is often a troublesome and enormous effort [22]. Various authors have discussed the importance of assessing the costs and time consumed by the execution of a process [1] [18] [20] [22] [24]. According to Wolf et al. [11] the identification of processes in public administrations should focus on those processes which produce the highest costs. The Federal Statistical Office, for instance, assesses the expenses for the processing of businesses-to-government (B2G) contacts on the basis of the standard cost model [30]. The corresponding data can be extracted from a public database. Various studies have assessed the costs of bureaucracy for specific industries (e.g., chemical industry [31]).

Quality, as discussed by Gaitanides [21], measures the error rate of products or services. Quality in this understanding is a measurement for the performance of process outputs, which are either products or services [18]. For tangible process outputs such as products the error rate is rather easy to assess. Gaitanides [21] fails to explain how the error rate should be measured in regard to services. Some researchers have attempted to define specific measures of service quality, i.e.: reliability, responsiveness, empathy, assurance, and tangibles [32]. Customer satisfaction is often clearly correlated with process quality. Therefore, customer satisfaction constitutes another key indicator for process performance [18].

Within the context of customer satisfaction Gaitanides [21] introduces the concept of value orientation. Value orientation focuses on the affiliation of processes to value chains from the customer's perspective [20] [21]. This approach assesses the 
individual value proposition of each activity to the entire value chain. Thus, all activities of a process must provide value to the production and/or delivery of the product to the customer. Activities that do not support a value chain are either redundant, inefficient, not purposeful, or not profitable [21]. The value proposition should be defined from the customer's perspective.

\subsection{Process Integration Indicators}

As organizations look to improve business processes, an important initial step is to understand the flow of information associated with the processes. Most public service processes stretch across different functional departments. Therefore, they often split across individuals and across time [24]. The flow of information is interrupted whenever information and data are not available at the required time in a sufficiently detailed manner. Consequently, information integration focuses on facilitating the seamless flow of information. The degree of information integration investigates how informational resources transfer across technical and organizational borders [5] [25]. Even though information integration constitutes the basis for integrated processes, it is not the only supposition for "fully integrated business processes" [24]. Other factors, such as the structure or non-ambiguity of data, can be equally influential.

The notion of timeliness in regard to information transfer becomes evident whenever one understands that process integration necessitates information integration. Timeliness assesses if the information is up to date [26] and available at the beginning of an activity. This understanding of timeliness assumes that information is accessible. Accessibility, in turn, implies that data need to be accessible from any point within the process [26]. The access to information needs to be dependable, convenient, and easily manipulated [28]. Additionally, information needs to be available at the right level of granularity. All information exchanged within the process has to be provided at the right level of detail [24] [26]. Appropriate granularity enables the elimination of extraneous activities that would be required to decompose or summarize the information. The last element concerns the transparency of information. The concept of transparency refers to the ease by which information is passed from one activity to another one [24] and implies a shared understanding of models and structure. According to Aubert et al. [26], there are two ways to achieve transparency; first, through translation among several "languages" or, second, through standardization. Hence, in regard to the transparency of a process, the level of standardization should be analyzed as well.

\subsection{Complexity Indicators}

At their initiation most processes are usually quite simple [20] but often grow considerably more complex over time. The more cases, variants, or actors that are involved, the more complex the process grows. Complexity indicators commonly disclose processes that can be simplified through integration.

Organizational complexity is generally examined from two perspectives: the company's side or the customer's side [29]. The latter plays a more prominent role in public reorganizations and optimizations since public service processes are characterized by a high degree of customer integration. The number of cases also 
increases complexity; for every service delivered on the municipality side there is a user on the citizen side [29]. A high number of user groups yield higher variants within and between the cases. In other words, complexity can be analyzed by the number of steps required to perform a process [27]. When integrating B2G processes, it appears critical to identify processes which affect the same group of users. The identification of users on the business side needs to be based on the type of business affected by the public service process and the role of the users' needs to be identified. Process bundling is generally desirable in areas distinguished by high case volumes and the same group of users. The reorganization or optimization of processes exhibiting a small number of cases, and therefore little complexity, is not desirable [29].

\subsection{Discussion of Findings}

The analysis of the literature review disclosed that there are at least three major principles (e.g., performance, process integration, and complexity) which support the elicitation of process bundling candidates. As mentioned, these three categories are not mutually exclusive. For instance, if a company embarks on a process reorganization project, performance indicators might be just as important for the identification of integration candidates as complexity or process integration indicators. However, none of the process reorganization and optimization concepts discussed above provide insights on how to prioritize the various criteria. Within this study we identified approximately 16 different criteria for the elicitation of bundling candidates. The analysis of all 16 indicators will not be feasible and purposeful in practice and more criteria might exist that we did not cover in our literature review. Therefore, it is extremely important to provide practitioners with guidelines on how to purposefully identify bundling candidates.

Our literature analysis also showed that the identification of adequate candidates for purposeful process bundling is not as straightforward as it may sound. Particularly within the complex setting of public institutions the existing set of identification criteria can be rather misleading. Current approaches to process identification promote a bottom-up identification of potential bundling candidates. These approaches start the identification process by choosing one or a selected number of processes that exhibit the greatest malfunctions. Accordingly, the improvement process always has one specific process as a starting point without providing a holistic picture of the process landscape. Process bundling is essentially concerned with changing or redirecting the flow of information between activities without changing the actual content of the information. In order to identify inefficiencies between processes one needs to study the corresponding information flow [25]. But none of the previously mentioned identification criteria support the comprehensive screening of several hundred public service processes. Based on the existing approaches, screening all public processes would be extremely time consuming and cost intensive. A top-down identification approach is needed within the public sphere in order to investigate the complex information flow between functional departments and companies and to identify relevant bundling candidates. Despite the abundance of existing identification criteria, we posit that the current set of criteria does not suffice and a top-down identification approach is necessary. 


\section{Synthesis - Introducing a Methodological Intermediary Step}

Within this section, we synthesize the analysis of the identified literature into a proposal for a methodological intermediary step in process bundling. This intermediary step addresses primarily the identification of B2G contacts. B2G contacts are commonly characterized by a higher degree of frequency and repetitions than citizen-to-government $(\mathrm{C} 2 \mathrm{G})$ contacts. The processing of $\mathrm{B} 2 \mathrm{G}$ contacts requires a considerable amount of time and resource capacities in companies which in return leads to higher costs of bureaucracy. By optimizing B2G processes, monetary and efficiency benefits can be achieved for both sides: companies and public administrations.

We propose that the identification and analysis of public service processes needs to encounter a top-down perspective. Tailoring the identification of processes to a superordinate principle (e.g., content, context, or business event) would yield a more anchored approach and account for the top-down perspective. We therefore propose a methodological intermediary step that promotes first a focus on primary process bundling principles and then on the commonly known identification criteria. In this view, primary principles are to be considered before secondary ones (see figure 1). Primary bundling principles assess the similarity or complementariness of the future process bundles in regard to their content, context, or a specific business event. It is crucial to understand that only one primary principle at a time can be pursued [11]. For instance, either the shared content or the shared context of processes can serve as the basis for further analysis. Processes with a similar or complementary content, even across departments, can then be analyzed in regard to their performance, efficiency, and complexity. The content and context based bundling principles stem from the feasibility studies [3] [13] funded by the German Federal Ministry of the Interior in 2009.

\begin{tabular}{|c|c|}
\hline & Primary Process Bundling Principles \\
\hline Content & Event \\
\hline Secondary Process Bundling Principles \\
Analyzing Criteria \\
(Performance, Process Integration, and Complexity) \\
\hline
\end{tabular}

Fig. 1. Primary and secondary process bundling principles

\subsection{Context Based Bundling}

Various value adding and support processes exist within companies that have multiple interfaces with public administrations. For instance, the award of a property credit exhibits contacts to the local tax office, the notary, the land registry office, and the bankruptcy court [13]. The context based bundling principle aims at guarantying the seamless flow of business processes and B2G contacts are bundled along the process flow. The key integration criterion for context based bundling is the affiliation of B2G 
contacts to business processes or process clusters. Subsequently, the identification of processes depends on their value adding context. There are various examples on how to identify bundling candidates based on their context affiliation. For instance, [13] examine B2G contacts of financial service providers on the basis of an industry specific process landscape. The affiliation of $\mathrm{B} 2 \mathrm{G}$ contacts to the same process cluster within the process landscape is used as an initial identification criterion. This context based affiliation helps the researcher in the identification and selection of process bundling candidates. In short, the context based bundling aims at identifying B2G contacts on the basis of their affiliation to a business process or cluster. Hence, this bundling principle necessitates the mapping of $\mathrm{B} 2 \mathrm{G}$ to affiliated processes.

\subsection{Content-Based Bundling}

Currently, the contacts of German companies with public administrations are characterized by a plethora of similar reporting and notification duties. The contentbased bundling principle assumes that these similar reports and notifications can be bundled based on their compatible content [3]. The content-based bundling principle aims at reducing the efforts needed to produce these reports and notifications while simultaneously guaranteeing and potentially increasing their quality. Content-based bundling focuses on exposing data and content redundancies between B2G processes. In this view, content and structural similarities of $\mathrm{B} 2 \mathrm{G}$ processes are crucial for the purposeful identification of bundling candidates [3]. In order to efficiently bundle $\mathrm{B} 2 \mathrm{G}$ contacts according to the content principle, the following conditions have to be fulfilled: (1) the contents of the processes exhibit a certain degree of similarity or redundancy, (2) the same user group, or companies respectively, have to be affected by the B2G contacts, (3) the direction of the information flow has to be congruent (e.g., in all cases from businesses to public administrations) [3]. These three conditions assure that synergies are used purposefully.

\subsection{Event-Based Bundling}

The event-based bundling principle assumes that certain business events recur in the life cycle of a company. These specific business events determine when companies need to get in touch with public administrations [33]. Examples of such events in the life cycle of a company are the registration of a business or the merger with another company. Both events force the company to get in touch with multiple functional departments in the public administration. The idea is to streamline these event-based B2G contacts in order to reduce processing errors and efforts on the side of the company. The bundling of business event contacts could potentially result in one government point of contact for the company. Event-based bundling is also discussed within the service domain where components are bundled based on their affiliation to a specific event. The event-based bundling principle has its theoretical foundations in the concept of one-stop government. One-stop government also assumes that information can and should be structured according to certain life events (Lebenslage). 


\section{Conclusion}

From our research we have determined that the combination of primary and secondary process bundling principles posits a collectively exhaustive lens for the purposeful identification of $\mathrm{B} 2 \mathrm{G}$ processes. We employed a rigorous procedure that generated the identification and analysis of 36 scholarly articles and books. These literature sources provided evidence that secondary identification principles are commonly comprised of performance, process integration, and complexity indicators. The mere employment of secondary identification criteria does not yield purposeful bundles of public service processes. The proposed methodological intermediary step which introduces content, context, and events as primary process bundling criteria fills this gap in current process identification research.

As practitioners look to improve public service processes, our research suggests that they should first focus on primary process bundling principles (e.g., content, context, and event). These principles would enable them to identify what processes can be bundled together while simultaneously providing insight on potential areas for improvement. Secondary process bundling principles support the elicitation of concrete weaknesses and discontinuities within and between processes. The introduction of public service process bundling is expected to reduce the amount of recurrent activities within public administrations. We suspect that the bundling of service processes will lead to fewer points of contact between businesses and public administrations which would in turn lead to cost reductions for both involved parties.

Multiple directions for further research exist. First, the purposeful identification of process bundling candidates remains ill-defined and should be exposed to more structured scrutiny. Second, the newly developed primary bundling principles need to be analyzed and further validated. Third, the transferability of bundling principles for the analysis of $\mathrm{C} 2 \mathrm{G}$ contacts needs to be investigated.

Acknowledgments. We would like to thank the German Federal Ministry of the Interior for their support and funding of the research project.

\section{References}

1. Scheer, A.-W., Nüttgens, M., Zimmermann, V.: Business Process Reengineering in der Verwaltung. In: Scheer, A.-W., Friedrichs, J. (eds.) Innovative Verwaltungen 2000, pp. 11-29. Wiesbaden, Gabler (2000)

2. Brüggemeier, M., Dovifat, A., Lenk, K.: Open Choice: Improving Public Sector Performance with Process Reorganization Methodology. In: Wimmer, M.A., Scholl, H.J., Grönlund, Å., Andersen, K.V. (eds.) EGOV 2006. LNCS, vol. 4084, pp. 186-194. Springer, Heidelberg (2006)

3. Wolf, P., et al.: Machbarkeitsstudie Prozessketten Umwelt. In: Lehrstuhl für Wirtschaftsinformatik, TU München, Siemens IT Solutions and Services, Berlin (2009)

4. Seethamraju, R., Marjanovic, O.: Role of process knowledge in business process improvement methodology: a case study. Business Process Management Journal 15(6), 920-936 (2009) 
5. Becker, J., Algermissen, L., Niehaves, B.: Organizational Engineering in Public Administrations - A Method for process-oriented eGovernment projects. In: Proceedings of the ACM Symposium on Applied Computing (2004)

6. Becker, J., Algermissen, L., Niehaves, B.: A procedure model for process oriented e-government projects. Business Process Management 12(1), 61-75 (2006)

7. Lenk, K.: Notwendige Revisionen des Geschäftsprozessdenkens. In: Wimmer, M.A. (ed.) Impulse für e-Government: Internationale Entwicklungen, Organisation, Recht, Technik, Best Practices, pp. 61-71. Österreichische Computer Gesellschaft, Wien (2002)

8. Zahlen, O.A., Bürokratieabbau, F.z.: (2009), http://www. bundesregierung. de/Content/DE/StatischeSeiten/Bre g/Buerokratieabbau/zahlen-und-fakten-zumbuerokratieabbau.html (cited February 15, 2010)

9. Hughes, O.E.: Public Management and Administration. 3rd edn., Palgrave Macmillan, New York (2003)

10. Porter, M.E.: Competitive Strategy. Free Press, New York (1980)

11. Wolf, P., Jurisch, M., Krcmar, H.: Analyse und Design von Prozessketten. In: Fachtagung Verwaltungsinformatik (FTVI), Koblenz (2010)

12. BMI, Bund Online 2005: Abschlussbericht - Status und Ausblick, Berlin (2006)

13. Fröschle, N., et al.: Machbarkeitsstudie Entwicklung von Prozessketten zwischen Wirtschaft und Verwaltung: Finanzdienstleistungen. Fraunhofer eGovernment Zentrum, Stuttgart (2009)

14. Sharafi, A., Wolf, P., Krcmar, H.: Process and data-oriented approach for bundling corporate reporting duties to public authorities - A case study on the example of waste management reporting. In: EGOV 2010. Springer, Lausanne (2010)

15. Innern, B.d. (ed.): BMI, E-Government 2.0 - Das Programm des Bundes. Bundesministerium des Innern, Berlin (2006)

16. Geng, X.S., Stinchcombe, M.B., Whinston, A.B., Hendershott, T.: Product Bundling. In: Hendershott, T. (ed.) Handbook of Economics and Information Systems, pp. 499-525. Elsevier, Amsterdam (2006)

17. Davenport, T.H.: Process Innovation: Reengineering work through information technology. Harvard Business School Press, Boston (1993)

18. Davenport, T.H., Beers, M.C.: Managing information about processes. Journal of Management Information Systems 12(1), 57-80 (1995)

19. Webster, J., Watson, T.R.: Analyzing the past to prepare for the future: writing a literature review. MIS Quarterly 26(2), xiii-xxiii (2002)

20. Hammer, M., Champy, J.: Reengineering the Corporation: A Manifesto for Business Revolution. HarperBusiness, New York (1993)

21. Gaitanides, M.: Prozessmanagement. Konzepte, Umsetzungen und Erfahrungen des Reengineering. Hanser Fachbuch, München (1994)

22. Harrington, H.J.: Business process improvement: the breakthrough strategy for total quality, productivity, and competitiveness, 23rd edn. McGraw-Hill, New York (2007)

23. 1021, D.-P., Verfahrensmodell zur Gestaltung von Geschäftsprozessen der öffentlichen Verwaltung - Wandel von der funktionalen zur prozessorientierten Verwaltung. 2003: Berlin

24. Berente, N., Vandenbosch, B., Aubert, B.: Information flows and business process integration. Business Process Managament Journal 15(1), 119-141 (2009)

25. Klischewski, R.: Information Integration or Process Integration? How to Achieve Interoperability in Administration. In: Traunmüller, R. (ed.) EGOV 2004. LNCS, vol. 3183. Springer, Heidelberg (2004) 
26. Aubert, B.A., Vandenbosch, B., Mignerat, M.: Towards the Measurement of Process Integration. In: Cahier du GReSI (2003)

27. Shostack, L.: Service positioning through structural change. Journal of Marketing 51, 34-43 (1987)

28. Strong, D.M., Yang, W.L., Wang, R.Y.: Data quality in context. Communications of the ACM 40(5), 103-110 (1997)

29. Becker, J.: Referenzmodellierung: Grundlagen, Techniken und domänenbezogene Anwendung. Physica-Verlag, Heidelberg (2004)

30. O.A., Einführung des Standardkosten-Modells Methodenhandbuch der Bundesregierung. Statistisches Bundesamt, Wiesbaden (2006)

31. Schulze, G.: Bürokratie- und Regulierungskosten in der chemischen Industrie - Potenziale zu ihrer Reduktion, Frankfurt am Main, Verband der Chemischen Industrie e.V. (2009)

32. Zeithaml, V.A., Berry, L., Parasuraman, A.: The Behavioral Consequences of Service Quality. Journal of Marketing 60, 31-46 (1996)

33. von Lucke, J.: Hochleistungsportale für die öffentliche Verwaltung. Joseph Eul Verlag $\mathrm{GmbH}$, Lohmar (2008) 